\title{
Assessment Design Through An EXPERT System AND ITS APPlication to A COURSE OF HYDRAUlics
}

\author{
Muhammad H. Imam ${ }^{1}$, Imran A. Tasadduq ${ }^{1}$, Muhammad H. Khan ${ }^{2}$, Abdul-Rahim Ahmad ${ }^{1}$, Fahd Aldosari ${ }^{1}$ \\ ${ }^{1}$ Umm Al-Qura University, Makkah Saudi Arabia \\ ${ }^{2}$ National University of Computer \& Emerging Sciences, Karachi, Pakistan \\ ${ }^{1}$ [mmimam, iatasadduq, anahmad, fmdosari]@uqu.edu.sa, ${ }^{2} \mathrm{k} 133007 @$ nu.edu.pk
}

\begin{abstract}
An assessment consists of questions addressing the required learning outcomes of a course. If a pool of questions of various types is made available then assessment design reduces to selection of questions, one by one, from the pool. Since the number of possible questions for a course may be quite large, and several preferences have to be matched, manual selection of a suitable question is not possible. This paper presents an enhanced implementation of a previously presented idea of a methodology for assessment design with an application to a course of Hydraulics with an initial pool of 1,000 questions. Each question is tagged with a set of attributes. The rules are generated by the expert system itself. The idea of a score of relevance has been introduced. The enhanced implementation displays a set of questions with their relevance scores rather than a single question to let the instructor choose from them. An instance of MS SQL Server at Azure database is used for the web-based cloud implementation.
\end{abstract}

Keywords: Expert system, student outcomes, course learning outcomes, question attributes.

\section{INTRODUCTION}

The purpose of a course in the curriculum of an academic program is to help the students attain certain abilities. These abilities are based on the subject matter of the course and are referred to as Course Learning Outcomes (CLOs). As a student goes through various courses of the curriculum, the CLOs attained from these courses in turn produce various broad abilities in the students by the time of graduation. These broad abilities must be in line with the mission of the program and the institution. Each accrediting agency specifies such broad outcomes and requires that the academic program seeking accreditation assesses these outcomes. For example, ABET specifies a set of such outcomes referring to them as Student Outcomes (SOs) [1].

The important thing to note here is that the SOs are not attained directly but through the CLOs. In an academic program, students enroll in a set of courses prescribed by the curriculum. The abilities attained by the students are attained mainly through these courses. The instructor teaching a course focuses on the subject matter so that at the end of the course the students attain the abilities as required by the set of CLOs pre-specified in the curriculum. The curriculum design must include courses with proper CLOs that also help in attaining the required SOs. This is usually done through a CLO-SO map [2-4]. Once this is ensured, teaching and assessment can be focused on the CLOs. Trying to assess the SOs directly and not through the CLOs defeats the purpose of the curriculum. For example, in a course of Circuit Theory, the CLOs require the students to attain an ability to analyze circuits, and in a course of Hydraulics, the CLOs require the students to attain the ability to analyze the flow in pipes and channels. These abilities in turn let the students attain the broad ability "to identify, formulate, and solve engineering problems" which is the ABET SO (e). Now, if an instructor just assesses the SO directly disregarding the subject matter, the whole idea of the curriculum is defeated. This note about the importance of CLO assessment is the key to effective assessment design which is the focus of this paper.

Assessment design requires selection of a set of questions for assessing students' abilities represented by the learning outcomes. The idea of a systematic methodology suitable for an Expert System (ES) has been presented in [2]. Other than this, no published work seems to exist that gives a systematic methodology for proper selection of a question in an assessment of learning outcomes considering the course topic, CLOs, SOs, the Bloom's Taxonomy level and other instructor's preferences. The usual practice has been to select a question, one by one, manually from a set of questions collected in the past from various sources. This collection of questions is improved by the instructor and more questions are added with time. The instructor keeps designing more and more questions going through the 
experience of teaching the course. This human process of selection or design of a question for assessment is rather intuitive based on the knowledge of the subject and the required outcomes. However, the pool of possible questions for a given subject is quite large and may run in thousands. In addition, several preferences have to be matched. In this situation, the manual selection of a suitable question is not possible without a systematic methodology. This leads to the idea of using an expert system to help in selecting a question based on instructor's preferences. First a brief background of expert systems is given.

An expert system [5-7] is a software package that simulates a human consulting with an expert in a given field for solving complex problems requiring knowledge and inferencing. It falls in the subject domain of artificial intelligence (AI). An expert system is different from conventional software architecture and programming. It is composed of a knowledge base, inference engine and an interface to interact with the user. The biggest advantage of an expert system as compared to conventional software is its ability to add/delete/modify the data in the knowledge base without altering the software. Expert systems have been used in many different fields. Huge number of publications exist on the application of the expert system [8, 9].

The ES presented in [2] has already presented the idea of the basic attributes of a question and was shown to work in a course of Circuit Theory with a very limited set of questions in the ES knowledge base. It was not tried with a big pool of questions. It finds only one question matching the user's preferences. Experiments with large pool of questions indicated that a number of questions may match the user's preferences. This paper presents an enhancement of the work presented in [2]. The idea of a relevance score has been introduced to help the instructor select from a set of questions that match instructor's preferences. The results of tests on a large pool of questions from the course of Hydraulics are presented. The ES database is also described.

\section{KNOWLEDGE BASE}

The ES works with a "Knowledge Base” (KB). It keeps growing and enhancing with time as the instructor or the subject expert keeps adding and modifying the elements of the KB. The KB contains the following data:

\subsection{Pool of questions}

The pool of questions is the most important part of the $\mathrm{KB}$. In this pool, each question is tagged for its attributes as described in Section 3.

\subsection{Course Content}

The course content is stored in the KB with each topic identified by “Topic ID”. This is required to let the ES display course contents so that the instructor can choose a topic. Each question is tagged with the relevant Topic ID.

\subsection{CLOs}

The CLOs are also stored with each CLO identified by an ID. The ES will display the list of CLOs for the course and the instructor will choose one of them. CLO ID tag is based on the CLOs of a course specified in the course syllabus. However, since a question may or may not be $100 \%$ belonging to a given CLO, the subject expert will also specify a "Relevance Score" for the CLO ID tag.

\subsection{SOs}

The SOs are also part of the KB and are displayed for the instructor. The instructor will choose one of them. SO ID tag is based on the pre-specified SOs of the academic program. Like the CLO ID, a "Relevance Score" for the SO ID tag is also required.

\subsection{Bloom's Levels}

Bloom's levels are also stored for the same purpose i.e. the instructor chooses a Bloom's level required by the ES for finding the proper question. Each question is judged and tagged for its Bloom's level with a "Relevance Score" indicating the quality of this judgment.

\subsection{Figure}

The "Figure Tag" is specified as "Yes" if the answer to the question requires a figure to be drawn otherwise specified as "No". "Relevance Score" is not required for this tag.

\subsection{Question Types}

All possible question types are stored in the $\mathrm{KB}$ and can be modified. They are displayed for the instructor to choose from. A Question Type Tag identifies whether the question requires a descriptive answer or, it is a numerical problem or, it is an MCQ. No "Relevance Score" for this tag is required. 
Based on the above, each question in the pool of questions is tagged with a set of attributes by the instructor or a subject expert as listed below:

1. Topic ID Tag

2. CLO ID Tag

3. SO ID Tag

4. Bloom's Level Tag

5. Figure Tag

6. Question Type Tag

7. Time Tag

\section{RULE BASE}

The "Rule Base" of ES resides in an inference engine. A rule is made of conditions and a consequent. Let $\chi_{i}$ denote the $i^{\text {th }}$ condition in the set of conditions stored in the rule base. All such conditions will be generated by the rule base. For example, $\chi^{1}$ is Topic ID $=1, \chi^{2}$ is Topic ID $=2$, and this will continue for all topic IDs. If the number of topics is 12, this set of conditions for the topics will end at $\chi^{12}$. Then the next condition will come from the CLO attribute and $\chi^{13}$ will be "CLO ID $=1$ ". This sequence will continue for all CLOs, and then for all SOs, Bloom's level and so on for all the attributes. The conditions will be determined by interaction of the ES with the instructor. For example, the ES asks the instructor to choose a topic for the question. If the instructor responds by selecting Topic 2 , the condition will be $\chi^{2}$.

Since there are seven tags associated with each question, each rule will have seven conditions. The consequent of the rule will be a set of questions satisfying all the seven conditions. Let this consequent be denoted by $\xi_{\mathrm{i}}$ for the $i^{\text {th }}$ rule. Here it must be noted that the consequent $\xi_{\mathrm{i}}$ is a set of all questions satisfying the rule with different values of the relevance score. A rule is expressed as follows:

$$
\text { If } \chi^{2} \& \chi^{14} \& \chi^{21} \& \chi^{27} \& \chi^{34} \& \chi^{47} \& \chi^{68} \text { THEN } \xi_{1}
$$

It means that when the set of attributes $\chi$ required in a question is satisfied, the consequent $\xi_{\mathrm{i}}$ is "fired", i.e., the ES outputs a set of questions that contain the desired attributes.

\section{HYDRAULICS QUESTIONS POOL}

For experimenting with the developed ES, a pool of questions from the course of Hydraulics was used. One thousand questions were collected from various sources. Each question was tagged for the seven attributes. Since the number of questions is quite large, the details of the questions cannot be given in this paper. Topic-wise distribution of questions is shown in Fig. 1. It is obvious that some topics have relatively fewer questions e.g., questions on the topic of Unsteady Flow are only 2\%, similarly Pipe Systems and Networks have only 4.4\%. But for testing purposes, it is not an issue. Questions on these topics may be added because it is usual for an expert system to grow and enhance with time.

The CLOs for the course and the CLO-wise distribution of questions is shown in Table 1. The SOwise distribution is shown in Table 2. It may be noted that this course addresses only four of the eleven ABET SOs [1] namely SOs (a), (b), (c) and (e).

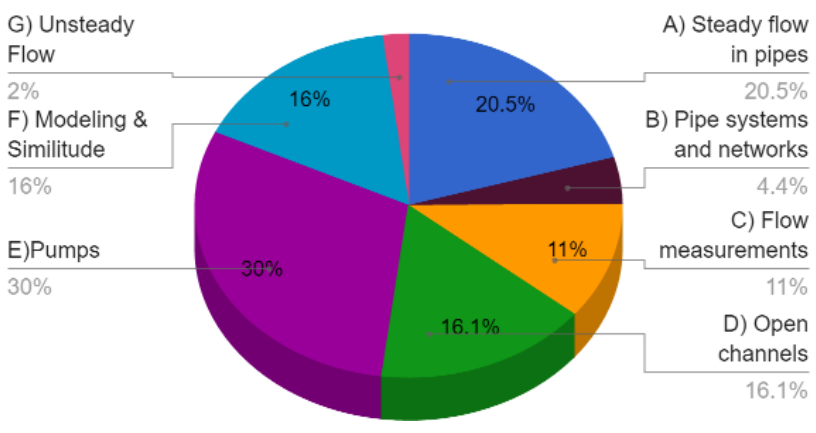

Fig. 1. Topic-wise distribution of questions in the KB.

Table 1: CLO-wise Distribution of Questions in the KB.

\begin{tabular}{|l|l|c|}
\hline \multicolumn{2}{|c|}{ Course Learning Outcomes (CLOs) } & $\begin{array}{c}\text { No. of } \\
\text { Questions }\end{array}$ \\
\hline 1 & $\begin{array}{l}\text { Ability to calculate flow in water } \\
\text { distribution systems and design networks }\end{array}$ & 259 \\
\hline 2 & $\begin{array}{l}\text { Ability to analyze flow in different types } \\
\text { of open channels }\end{array}$ & 171 \\
\hline 3 & $\begin{array}{l}\text { Ability to conduct experiments of flow } \\
\text { measurements through pipes and open } \\
\text { channels }\end{array}$ & 269 \\
\hline 4 & $\begin{array}{l}\text { Ability to design and select different types } \\
\text { of pumps. }\end{array}$ & 301 \\
\hline
\end{tabular}

Table 2: SO-wise Distribution of Questions in the KB.

\begin{tabular}{|c|c|c|}
\hline \multicolumn{2}{|r|}{ Student Outcomes (SO) } & $\begin{array}{c}\text { No. of } \\
\text { Questions }\end{array}$ \\
\hline (a) & \begin{tabular}{|l} 
An ability to apply knowledge of \\
mathematics, science, and engineering
\end{tabular} & 276 \\
\hline (b) & \begin{tabular}{|lrrr} 
An ability to design and conduct \\
experiments, ...
\end{tabular} & 268 \\
\hline (c) & $\begin{array}{l}\text { An ability to design a system, component, } \\
\text { or process to meet desired needs ... }\end{array}$ & 293 \\
\hline (e) & $\begin{array}{l}\text { An ability to identify, formulate, and } \\
\text { solve engineering problems }\end{array}$ & 163 \\
\hline
\end{tabular}




\section{AN APPLICATION EXAMPLE}

A typical problem is presented here to demonstrate the working of the developed ES. Table 3 shows the instructor's preferences.

Table 3: Instructor's Preferences.

\begin{tabular}{|l|l|l|}
\hline \multicolumn{2}{|c|}{ Attribute } & \multicolumn{1}{c|}{ Preference } \\
\hline 1 & Course Topic & Flow in open channels \\
\hline 2 & CLO & 4 \\
\hline 3 & SO & (a) \\
\hline 4 & Bloom's Level & 3 \\
\hline 5 & Figure required & No \\
\hline 6 & Question Type & Numerical \\
\hline 7 & Time to solve & 15 minutes \\
\hline
\end{tabular}

These preferences were input through the ES interface. The snapshot of the display of results is shown in Fig. 2. Each question in this display satisfies the instructor's preferences and has been given a relevance score. The user can click the view button to view the details of any of the selected question.

\begin{tabular}{|c|c|c|c|}
\hline \multirow{2}{*}{\multicolumn{2}{|c|}{ Question Statement }} & \multicolumn{2}{|c|}{ Relevance View } \\
\hline & & Score & Details \\
\hline 1 & $\begin{array}{l}\text { What do you mean by 'Most- } \\
\text { economical section' of an } \\
\text { open channel? How is it } \\
\text { determined? }\end{array}$ & 102 & View \\
\hline 2 & $\begin{array}{l}\text { Compare the rectangular, } \\
\text { triangular, trapezoidal and } \\
\text { circular cross-sections of } \\
\text { open channel. }\end{array}$ & 99 & View \\
\hline 3 & $\begin{array}{l}\text { Derive expression for critical } \\
\text { depth and critical velocity } \\
\text { related to flow through } \\
\text { channel. }\end{array}$ & 99 & View \\
\hline
\end{tabular}

Fig. 2. ES Output Satisfying Instructor's Preferences.

\section{DATABASE DESIGN}

The database used for the implemented expert system is Microsoft SQL Server. An instance of MS SQL Server at Azure database services is used because the Azure services are secure and will allow us to increase the instances of databases in future as the usage increases. Azure also supports clustered environment of instances of database which will perform the load balancing of database requests and also mitigate the failure of services by utilizing the running instances even if other few instances are malfunctioned. MS SQL Server Management Studio is used to manage the database tables shown in Fig. 3. The tables are described as follows:
1. Q_QUESTION stores Course ID, Program ID, CLO ID, SO ID, Course Topic ID)

2. Q_ATTRIBUTE stores the tags/attributes information. These tags will be assigned to each of the question. This table also stores the weightage for each tag. An example of a tag is "Does the student require to draw a figure?”

3. Q_ATTRIBUTE_OPTION stores the options for each tag. For the example tag of "Does the student require to draw a figure?" the options will be "Yes" and "No". The Q_Attribute_attribute_id column is the foreign key of Q_ATTRIBUTE table.

4. QUE_ATTRIBUTE_WEIGHTAGE stores weightage for the tags. When searching for the questions, user's preferences provided for these three tags matching the question will be picked and suggested by the system. While for other tags, if they do not match, questions might still be suggested by the system based on higher scores of questions calculated by the system.

5. Q_QUESTION_SCORE stores the score values assigned to the tags i.e., CLO, SO and Course Topic when adding the question. The QUESTION_ID column is the foreign key of Q_QUESTION table.

6. Q_Question_Attribute_Option stores the tags information assigned to each question. It will also store the score for each tag. The Q_QUESTION_QUESTION_ID column is the foreign key of Q_QUESTION table, and Q_Attribute_Options_attribute_option_id column is the foreign key of Q_ATTRIBUTE_OPTIONS table.

7. Q_Favorite_List, stores information for new assessment.

8. Q_Favorite_List_has_Q_Question stores questions selected for the assessment. The Q_Question_question_id column is the foreign key of Q_QUESTION table.

9. APP_CODE table stores setup data in name value pair format. The value will be referenced in tables so that the name might be changed in future without affecting the values used in the referenced table.

10. APP_CODE_TYPE stores a type in name value pair format for the APP_CODE table values. 


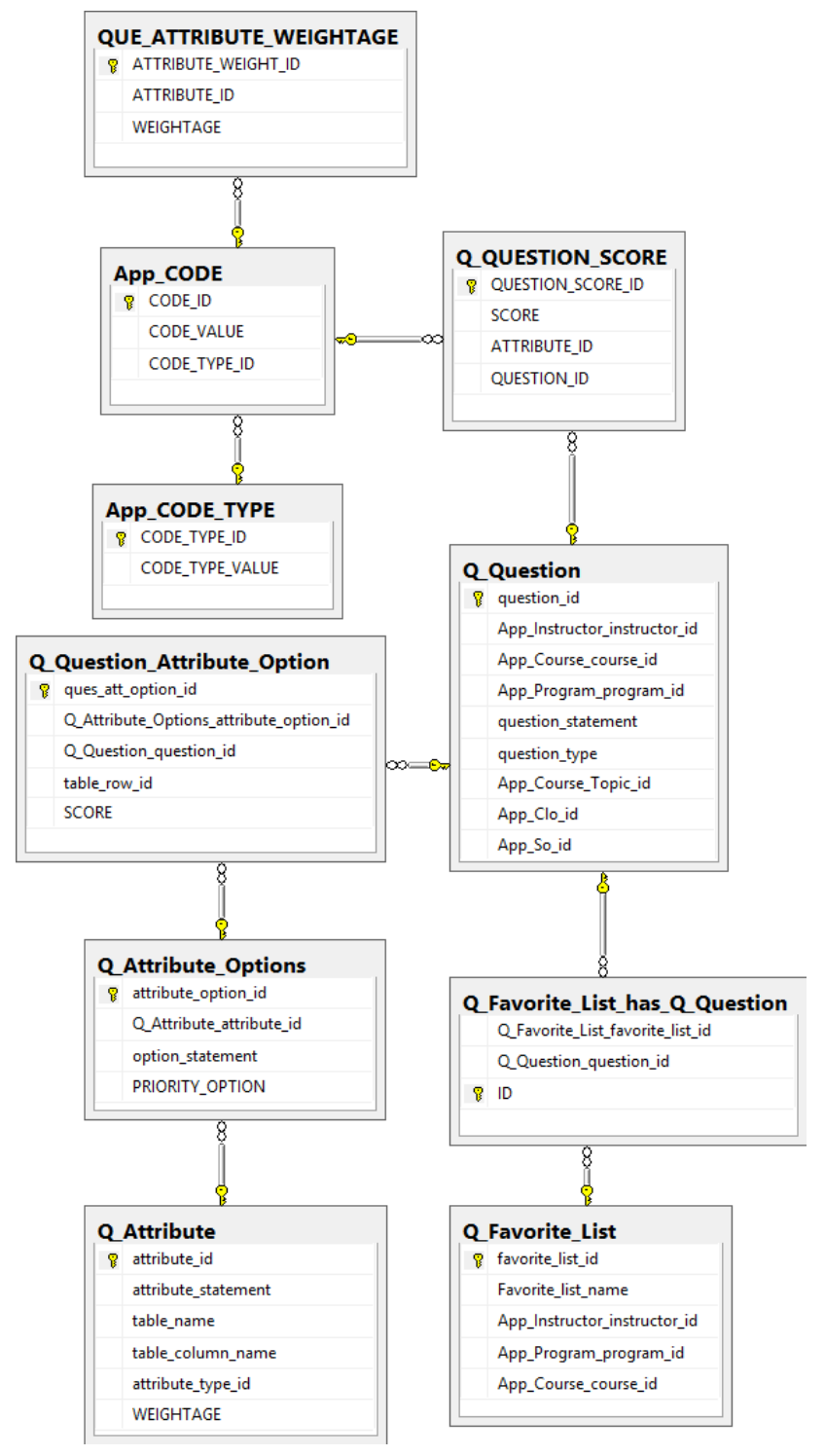

Fig. 3. Database Schema for the ES

\section{CONCLUSIONS}

An enhanced expert system has been presented for assessment design in engineering education. The knowledge base contains a pool of questions with other data related to course topics and learning outcomes. Each question in the knowledge base is tagged with values for seven common attributes applicable to all questions. The database used has been described. The instructor's input consists of the preferences about the attributes of the questions. Based on these preferences, ES finds out a set of questions matching the instructor's preferences. A relevance score for each question selected by the ES is generated. The ES is a web-based cloud implementation. It was applied to a course of Hydraulics. For this course one thousand questions of various types were collected. The ES allows adding new questions and modifying the existing ones. The ES has the potential of becoming a routine tool for instructors in assessment design ensuring the required learning outcomes are assessed properly. It is obvious that the task performed by the presented ES cannot be accomplished manually considering all aspects of assessment design. The enhanced ES presented in this paper is close to a practical tool, though still under further development. This ES has a few issues that require further research. The most important is to take into account the fuzzy nature of some of the preferences the instructor specifies and the tags associated with each question. The attributes of a question also need to be improved and more attributes have to be added. The interface needs to be further improved.

\section{Acknowledgements}

This work was funded by the National Plan for Science, Technology and Innovation (MAARIFAH) King Abdulaziz City for Science and Technology - the Kingdom of Saudi Arabia, award number 13-INF1094-10.

\section{References}

ABET. (2016, 19 April). Student Outcomes. Available: http://www.abet.org/accreditation/accreditationcriteria/criteria-for-accrediting-engineering-programs2016-2017/\#outcomes

I. A. Tasadduq. M.H. Imam, Abdul-Rahim Ahmad, Fahd Aldosari, "An Expert System for Assessment of Learning Outcomes for ABET Accreditation," presented at the International Conference on Engineering Education, Singapore, 2016.

M. H. Imam and I. A. Tasadduq, "Evaluating the satisfaction of ABET student outcomes from course learning outcomes through a software implementation," International Journal of Quality Assurance in Engineering and Technology Education (IJQAETE), vol. 2, pp. 21-33, 2012.

[4] Smart-Accredit, "CLOSO User's Manual," 2016.

[5] P. Jackson, Introduction to Expert System: AddisonWesley, 1998.

[6] R. G. Giarratano J. , Expert Systems: Principles and Programming. Boston: PWS Publishing Company, 2004.

[7] M. Stefik, Introduction to knowledge systems: Morgan Kaufmann, 2014.

[8] H. K. Jabbar and R. Z. Khan, "Survey on development of expert system in the areas of Medical, Education, Automobile and Agriculture," in Computing for Sustainable Global Development (INDIACom), 2015 2nd International Conference on, 2015, pp. 776-780.

[9] M. M. Umar, A. Mehmood, and H. Song, "A Survey on State-of-the-Art Knowledge-based System Development and Issues," SmartCR, vol. 5, pp. 498509, 2015. 